\title{
ESTIMATING CONSUMER'S WILLINGNESS-TO-PAY FOR PARTICIPATION IN AND TRAVELING TO MARATHON EVENTS
}

\author{
PAMELA WICKER* AND KIRSTIN HALLMANN $\dagger$ \\ *Department of Tourism, Leisure, Hotel and Sport Management, Griffith University, \\ Gold Coast Campus, Southport, Queensland, Australia \\ $\dagger$ Institute of Sport Economics and Sport Management, German Sport University Cologne, \\ Cologne, Germany
}

\begin{abstract}
Although research on marathon running has gained in importance during recent years, a lack of research regarding the economic aspects of marathon runners has been clearly identified. The purpose of this study was to investigate the willingness-to-pay (WTP) for participation in and traveling to marathon events. Data on marathon runners in Germany were collected using a nationwide online survey $(n=285)$. Behavioral, psychographic (opinion), and demographic variables were used to explain the WTP for traveling to a marathon in Germany, in Europe, and overseas. Respondents were found to be willing to pay on average $€ 270$ for traveling to a marathon event in Germany, $€ 568$ to one in Europe, and $€ 1,429$ to an overseas marathon. The factor analysis showed that the psychographic variables could be summarized in four factors labeled casual, health-conscious, identitydriven, and switching. The regression results revealed that particularly psychographic (healthconscious, casual) and demographic variables (income) were significant determinants of WTP.
\end{abstract}

Key words: Participant behavior; Willingness-to-pay (WTP); Marathon runner;

Active sport consumption; Pricing; Psychographics

\section{Introduction}

Marathon running has received a lot of attention in terms of consumers taking part in marathon races and researchers dealing with marathon runners in various studies over several years (e.g., Cobb \& Olberding, 2007; Hallmann, Kaplanidou, \& Breuer,
2010; Ogles \& Masters, 2003). The high number of people taking part in marathon races is underpinned by the number of events that take place annually. For instance, Germany hosted more than 180 marathons in various cities and regions in 2010 (Statista $\mathrm{GmbH}, 2011$ ). Major races like the Boston, London, Berlin, Chicago, or New York Marathon have

Address correspondence to Pamela Wicker, Department of Tourism, Leisure, Hotel and Sport Management, Griffith University, Gold Coast Campus, Parklands Drive, Southport Queensland 4222, Australia. Tel: +61-7-555-28552; Fax: +61-7-555-28507;

E-mail: p.wicker@griffith.edu.au 
a high number of participants and many crowds cheering along the course. Marathon runners take part in marathon races all over the world and were found to collect places; that is, they preferred not to participate always in the same marathon event, but rather to take part in races in different cities (Shipway \& Jones, 2008).

Participants in marathon events can spend a lot of money on registration fees and traveling, and consequently, a marathon race can create a positive impact for its host city (e.g., Daniels \& Norman, 2003; Pennington-Gray \& Holdnak, 2002). Therefore, it is of interest for event managers of marathon races to know more about the economic aspects of marathon participants and to understand what marathon runners are willing to pay for a specific running experience and for the overall journey. In particular, event organizers are interested in how much they can charge in order to get entry to a race. Some event organizers do not consider raising registration fees because they are afraid of losing participants. Therefore, information about the participants' willingness-to-pay (WTP) is relevant to them because many participant sport events have difficulties in financing themselves only through registration fees. Depending on the event and the city, the fees for closing roads and stopping public transport can be quite expensive. Therefore, event organizers have to search additional income sources such as sponsorship income, which can prove difficult in times of economic crisis. Although a growing body of research about the marathon runner as a consumer could be identified, the WTP for the experience of activity, place, and people (Weed \& Bull, 2004) has been neglected in previous research.

This study aims to analyze the WTP of marathon runners for participation in and traveling to marathon races. Thereby, it must be taken into account that the overall price of sport consumption consists of several components (Gratton \& Taylor, 2000). For example, participants of marathon events do not only pay the registration fee, they can also have additional expenses for accommodation (e.g., hotel, hostel) and travel (e.g., flight, public transport, fuel costs of car). All these expenses are summarized under traveling expenses. The decision to participate in a specific event is thus not only driven by the registration fee, but rather by the total costs of participation in the event. Therefore, both
WTP for taking part in the marathon itself (registration fee) and WTP for the overall journey (traveling expenses) are included in the current study. The study has the following two main research questions: (1) What are consumers willing to pay to take part in marathon events and travel to marathon events? (2) What are the key determinants of WTP for traveling to marathon events? This study contributes to the body of research on marathon running and on WTP for active sport consumption. The findings have implications for event managers as they enable more targeted pricing policies.

\section{Literature Review and Conceptual Framework}

\section{Marathon Runners}

Consumers of marathon races were found to share similar characteristics. Previous research findings indicate that the average age of marathon participants is around 40 years and that participants were mainly male (Chalip \& McGuitry, 2004; Funk, Toohey, \& Bruun, 2007; Hallmann et al., 2010; Kaplanidou, Funk, Buta, \& Goutzioupas, 2009; Scheerder, Vos, $\&$ Pauwels, 2009). Marathon runners could be characterized by a high educational level (e.g., Funk et al., 2007; Scheerder et al., 2009) and relatively high income (e.g., Funk et al., 2007). Previous research has shown that marathon runners took marathon races very seriously and there was evidence that "the travel element enhances the salience of participants' sporting identity" (Shipway \& Jones, 2008, p. 74).

In prior studies, the marathon runner has been analyzed from various perspectives such as motivation (Funk et al., 2007; Ogles \& Masters, 2003; Shipway \& Jones, 2008), consumer profile (Scheerder et al., 2009), and perceived event image (Hallmann et al., 2010). There was evidence that runners would form particular subcultures (Shipway \& Jones, 2008) and that they would identify themselves immensely with the activity (Shipway \& Jones, 2007, 2008; Yair, 1990). Strong links between taking part in the race and travel motives have also been identified referring to, for instance, cultural experiences (Funk et al., 2007). The experience orientation, being health conscious, and the question of life balance were all dominant themes in leisure and tourism (Mikunda, 2002; Pine \& Gilmore, 1999). Running a marathon could offer such an experience and result in runners feeling healthy and fit. 
The expenditure at marathon races has been investigated in previous research. To provide a few examples, the average daily spending per marathoner was found to be between US\$82 (Daniels \& Norman, 2003) and US\$580 (Cobb \& Olderling, 2007). These figures show that expenditure at marathon events can differ among events and studies. Moreover, sociodemographic variables were found to have a significant effect on expenditure at marathon events. In previous research, age had a positive effect on expenditure (Daniels \& Norman, 2003), indicating that older people tended to spend more money than younger people. Income was also found to be positively correlated with expenditure, meaning that consumers with higher income spent more money than consumers of lower economic status (e.g., Cannon \& Ford, 2002; Chhabra, Sills, \& Rea, 2002; Daniels \& Norman, 2003).

\section{Willingness-to-Pay}

Generally speaking, WTP is the maximum price consumers are willing to pay for a certain product (Diller, 2000; Kalish \& Nelson, 1991) and it represents the upper limit of the acceptable price range of a product (Balderjahn, 2003). The most common method for measuring the WTP for a specific product is a direct approach using an open-ended question (Carson, Wright, Carson, Alberini, \& Flores, 1993). Stated WTP is determined by the economic value and the utility the product has to the consumer (Breidert, 2005). Thus, it also includes a subjective component (Kalish \& Nelson, 1991) because the same product might be of different utility and value to different consumers leading to differences in their WTP. According to Balderjahn (2003), consumers are able to imagine the maximum price they would pay for a product even without having access to pricing information.

The main criticisms of WTP are the hypothetical and strategic bias. A strategic bias is present when consumers intentionally underestimate their WTP because they assume that price increases are implemented when they state a higher WTP (Rollins \& Trotter, 1999-2000). A hypothetical bias comes from the fact that WTP is a hypothetical construct, and the question is whether consumers would be really willing to pay the maximum price they stated. A hypothetical bias would be present when consumers have significantly overstated their WTP. This bias was evident in some studies (Johannesson, Liljas, \& Johansson, 1998; Seip \& Strand, 1992), whereas other studies could not support the existence of a hypothetical bias because there was no significant difference between hypothetical and actual WTP (Carlsson \& Martinsson, 2001; Sattler \& Nitschke, 2003). In summary, measuring WTP directly using an open question was found to be a valid approach, particularly compared with indirect approaches such as conjoint analysis (Sattler \& Nitschke, 2003).

The review of previous WTP studies focuses on WTP for active sport consumption as no studies on WTP for participation in marathon are available up to now. Several studies have assessed the WTP for community sport programs. In a Canadian study, average WTP per household for increases in sport and recreation programs amounted to CA \$18 (Johnson, Whitehead, Mason, \& Walker, 2007). In a German study, stated WTP for the yearly membership fees in community sport clubs was $€ 265$ on average and almost twice as high as the average current membership fee of $€ 148$. The results also revealed that sport-specific differences have to be taken into account, as stated WTP ranged from $€ 114$ in skiing to $€ 1,578$ in golf (Wicker, 2011). Previous research has indicated that consumers' WTP can be influenced by several determinants. Income was found to impact positively on stated WTP as people with a higher income stated higher WTP values (e.g., Atkinson, Mourato, Szymanski \& Ozdemiroglu, 2008; Owen, 2006; Wicker, 2011). Education also had a positive impact on stated WTP in previous studies (e.g., Süssmuth, Heyne, \& Maennig 2010; Wicker, 2011). In addition to sociodemographic variables, behavioral variables such as weekly time of participation and level of performance had a positive influence on WTP (Wicker, 2011). The review of the literature reveals the lack of research regarding WTP for participation in marathon races, and therefore the current body of research would benefit from such a study.

To address this lack of research, the WTP for participation in marathon events is investigated in the current study. A set of consumer segmentation variables is used to explain WTP. According to the sport marketing literature, sport consumers are heterogeneous, and therefore sport marketers 
try to segment the overall consumer base into several smaller market segments (Mullin, Hardy, \& Sutton, 2007). In doing so, demographic, psychographic, and behavioral segmentation procedures and variables are used, preferably in combination with each other to provide a full picture of the sport consumer (Shilbury, Westerbeek, Quick, \& Funk, 2009). Demographics relate, for example, to a consumer's age, gender, and income (Shilbury et al., 2009). Psychographics can be defined as "quantitative research intended to place consumers on psychological-as distinguished from demographic dimensions" (Wells, 1975, p. 197) and includes consumer's opinions (Wells, 1975). Behavioral aspects relate to sport practice aspects such as frequency and intensity of participation (Shilbury et al., 2009). Evidently, demographics present the foundation of segmentation that is enriched by psychographic and behavioral segmentation variables (Rohm, Milne, \& McDonald, 2006; Trail \& James, 2001). Given the subjective nature of WTP, it is suggested that WTP differs among marathon runners with various demographic, psychographic, and behavioral characteristics.

\section{Method}

\section{Data Collection and Sampling Procedures}

A survey was conducted by sending out a link to an online self-completion questionnaire. For publishing the link, different sources were used, namely, (1) a newsletter of a company that is responsible for timing marathon races in Germany $(90,000$ recipients), (2) the homepage of that company, (3) a newsletter of a running website (20,000 recipients), and (4) the homepage of the running website. Integrating the link into the newsletter and publishing the link on the website of the company was possible due to personal contacts. This sampling frame was selected because the total number of recipients of the newsletters seemed attractive. The newsletters were sent out on February 21, 2011, and the link on each homepage was available for 4 weeks. There was no incentive available for taking part in the survey. A nonprobability sample, namely, a convenience sample, was used. In total, $n=285$ runners completed the questionnaire, resulting in a response rate of $0.003 \%$. According to the contact persons who sent out the newsletter, this response rate can be considered common because they had previously experienced similar response rates when trying to activate the running community.

Nevertheless, the response rate and sample size need further attention. Evidently, the use of several newsletters and the website was not the best option to draw the sample for this study. However, a statement that newsletters are not useful in general cannot be made because using them was quite successful in previous research (Bojanic \& Warnick, 2012; Mead, Ford, Roth, Beach, \& Klag, 2000). Another possibility to draw the sample would have been to attend marathon events and to distribute a paper questionnaire at the event in person. However, the question is when is it a good point in time to survey the marathon runners. It is suggested that they are too focused before the marathon and probably too exhausted after it. Furthermore, there was not enough man power to distribute and collect thousands of questionnaires at the marathon. Also, the length of the questionnaire was another reason why the authors decided not to choose this option. Apart from another way of distributing the questionnaire, an incentive could have been integrated in the questionnaire to increase the response rate (van Selm \& Jankowski, 2006). Whereas the positive effect of using incentives in mail surveys was evident in prior studies (e.g., Brennan, 1992; Shank, Darr, \& Werner, 1990), the success of the incentive depends on the type of incentive in the online survey (Bosjnak \& Tuten, 2003; Cobanoglu \& Cobanoglu, 2003). However, as the current study was not funded, an incentive could not be afforded.

With regard to sample size, it has to be mentioned that previous studies on marathon runners were also based on relatively small sample sizes (e.g., Chalip \& McGuirty, 2004; Funk et al., 2007; Kruger \& Saayman, 2012). Moreover, Bortz (2005) suggests a sample size of $n=300$, which is not too far away from the current sample size $(n=285)$. The literature on research methods also indicates that not the sample size but rather the structure of the sample and its representativeness regarding the total population in terms of specific characteristics are important (e.g., Singer, 2002). The total population would be the (marathon) running community 
in this case, and therefore, the sample structure of the current study is compared with previous studies to check whether the typical marathon runners have participated in the survey.

\section{Measures and Variables}

The questionnaire was designed for the purpose of the current study and consisted of 35 questions in total. It was equivalent to seven pages in written form. In the introduction to the online questionnaire and the e-mails that included the link to the online questionnaire, respondents were told that the questionnaire would be for a research project on marathon events and that it would take approximately 10 to $15 \mathrm{~min}$ to complete it. They were reassured that the data would be analyzed anonymously and used only for scientific purposes.

A set of behavioral, psychographic (opinion), and demographic variablesresulted from thequestionnaire (for an overview of the variables, see Table 1). With regard to behavioral variables, respondents were asked to state the number of kilometers they were running per week (KM) and the number of participations in marathon races per year (MAR). The psychographics were assessed using a list of statements addressing the opinion of the respondents. Respondents were instructed to state on 5-point Likert scales to what extent they agreed with each statement. They were asked whether they think of themselves as a runner (SELF), whether running would be good for health (HEALTH), whether they would stop running if they had less time (STOP TIME), whether they would feel emotionally attached to other runners (ATTACH), whether runners would significantly differ from other sportsmen (DIFF), whether running could be easily integrated into everyday life (ALLDAY), whether running would be good for mental relief (MENTAL), whether one reason for running would be that the sport can be practiced

Table 1

Overview of Variables

\begin{tabular}{|c|c|c|}
\hline Variable & Description & Scale \\
\hline WTP_GER_MAR & WTP for registration fee of a marathon in Germany (in $€$ ) & Metric \\
\hline WTP_EU_MAR & WTP for registration fee of a marathon in Europe (in $€$ ) & Metric \\
\hline WTP_SEĀ_MAR & WTP for registration fee of a marathon overseas (in $€$ ) & Metric \\
\hline WTP_GER_TRA & WTP for traveling to a marathon in Germany (in $€$ ) & Metric \\
\hline WTP EU TRA & WTP for traveling to a marathon in Europe (in $€$ ) & Metric \\
\hline WTP_SEĀTRA & WTP for traveling to a marathon overseas (in $€$ ) & Metric \\
\hline LN WTP_GER_TRA & Natural log of WTP_GER_TRA & Metric \\
\hline LN WTP_EU_TRA & Natural log of WTP_EU_TRA & Metric \\
\hline LN WTP SEĀ TRA & Natural $\log$ of WTP SEA & Metric \\
\hline \multicolumn{3}{|l|}{ Behavior } \\
\hline KM & Weekly practice (in kilometers per week) & Metric \\
\hline MAR & Number of participations in marathon races per year & Metric \\
\hline \multicolumn{3}{|c|}{ Psychographics (opinion; assessed on 5 -point Likert scales from $1=$ do not agree at all to $5=$ totally agree) } \\
\hline SELF & I think of myself as a runner. & Ordinal \\
\hline HEALTH & Running is good for health. & Ordinal \\
\hline STOP TIME & I would stop running if I had less time available. & Ordinal \\
\hline ATTACH & I feel emotionally attached to other runners. & Ordinal \\
\hline DIFF & Runners significantly differ from other sportsmen. & Ordinal \\
\hline ALLDAY & Running can easily be integrated into everyday life. & Ordinal \\
\hline MENTAL & Running is good for mental relief. & Ordinal \\
\hline PLACE & One reason for running is that the sport can be practiced everywhere. & Ordinal \\
\hline ENDUR & Running is good for endurance. & Ordinal \\
\hline \multicolumn{3}{|l|}{ Demographics } \\
\hline GENDER & Gender of the marathoner $(1=$ male $)$ & Dummy \\
\hline AGE & Age of the marathoner (in years) & Metric \\
\hline EDU & $\begin{array}{l}\text { Highest educational level attained }(1=\text { at least } \mathrm{A} \text { levels, university entrance } \\
\text { diploma in Germany; } 0=\text { else })\end{array}$ & Dummy \\
\hline INC & Monthly net income of the marathoner (from $1=$ up to $€ 500$ to $9=$ over $€ 4,000$ ) & Ordinal \\
\hline
\end{tabular}


everywhere (PLACE), and whether running would be good for endurance (ENDUR). The questionnaire finished with a set of questions assessing the respondents' demographics (GENDER, AGE, INC). The educational level of the respondent was assessed by offering five answer categories (from $1=$ primary school to $5=$ university degree). The variable EDU was obtained by recoding the parameter values 4 (A levels) and 5 (university degree) into 1 and all else into 0 (Table 1).

The WTP for participation in and traveling to marathon events was asked in the mid third of the questionnaire using open questions. Generally speaking, WTP can be measured using open questions (i.e., respondents fill in a number) or closed questions (i.e., respondents are provided with several specific euro values or ranges as answer possibilities and tick one of these). Usually, closed questions are used when it is assumed that the cognitive effort respondents have to make would be too high (Klose, 1999), for example, because they have no idea about the price structure of the product. However, this should not apply to the current study because marathon runners are aware of the price they pay for participation and traveling to marathon events because they have done it before (otherwise they would not receive the newsletters and would not be part of the sample). Moreover, a starting point bias can be present in a closed question (Völckner, 2006). Because several answers are provided, the price range is already specified and leaves no room for individual completion. Another shortcoming of the closed question is the type of variable resulting from the question. The closed question results in a nominal or at best ordinal variable (if the distances between the provided prices or the price intervals are identical), whereas the open question results in a metric (continuous) variable. The metric variable is of higher quality because it offers more opportunities for data analysis (Bortz, 2005); for example, it can be entered into a linear regression analysis. It also provides more information for event managers because an average WTP can be calculated. For the abovementioned reasons, the authors decided to use an open WTP question.

First, the WTP for the registration fee of a marathon event was assessed with the following question: What is your maximum willingness-to-pay for participation in the following marathon events?
Respondents were asked to state their WTP for three types of marathon events, that is, a marathon race in Germany (WTP_GER_MAR), a marathon race in Europe (WTP_EU_MAR), and a marathon race overseas (WTP_SEA_MAR). Second, respondents were asked to state their WTP for traveling to marathon events using the following question: What is your maximum willingness-to-pay for traveling (including travel and accommodation) to the following marathon events? WTP was assessed for the same types of marathon events in Germany (WTP_GER_TRA), in Europe (WTP_EU_TRA), and overseas (WTP_SEA_TRA) (Table 1). The WTP questions were general questions that did not specify the different marathon races; that is, it was not specified which particular marathon in Germany the respondents should think of. Providing a list of all possible marathons did not seem feasible given the fact there are over 180 marathons only in Germany every year (Statista GmbH, 2011). The authors decided to ask for general information because it was the first study that analyzes the WTP for participation and traveling to marathon events.

\section{Data Analysis}

The data analysis consisted of three main steps. First, the data were checked for content validity and implausible figures were set to missing values. Particularly the WTP values have been checked for plausibility given the possibility of a hypothetical bias (Johannesson et al., 1998). To give some details of the variable distributions, the maximum values for WTP for participation in and traveling to a marathon event were $€ 300$ and $€ 1,000$ (Germany), $€ 700$ and $€ 5,000$ (Europe), and $€ 1,500$ and $€ 6,000$ (overseas marathon), respectively. As all values seemed meaningful and were in a realistic price range, no adjustments had to be made to the data. Descriptive statistics were provided to give an overview of the sample structure and to answer the first research question (What are consumers willing to pay to take part in and travel to marathon events?). Second, an explorative principal components factor analysis using varimax rotation was conducted to reduce the number of psychographic variables to a smaller number of factors (Späth, 1975). In a third step, log-linear regression analyses were estimated 
to answer the second research question (What are the key determinants of WTP for traveling to marathon events?). Altogether, three regression models were estimated with the three WTP variables for traveling to the marathon event as the dependent variables. The natural $\log$ of the WTP variables was used because it represents the "real" relationships between variables and consequently improves the explanatory power of the models. In all models, the psychographic factors resulting from the factor analysis, the behavioral variables (KM, MAR), and demographic variables (GENDER, AGE, EDU, INC) served as independent variables. Regression models with robust standard errors were estimated to control for heteroscedasticity (MacKinnon \& White, 1985; White, 1980). Moreover, the check for multicollinearity indicated no problems of multicollinearity as all variance inflation factors were below 10 (Hair, Black, \& Babin, 2006) and all correlation coefficients below 0.9 (Tabachnick \& Fidell, 2007). An $\alpha$ level of 0.1 was used for all statistical tests.

\section{Results \\ Participant Characteristics}

The descriptive statistics are summarized in Table 2. The demographic variables show that $75.0 \%$ of the respondents were male and that $65.7 \%$ had at least A levels, the university entrance diploma in Germany. On average, the respondents were 44.76 years old and their monthly net income amounted to 5.67 which is equivalent to $€ 2,001$ to $€ 2,500$. With regard to behavioral variables, the respondents stated that they would run $54.27 \mathrm{~km}$ per week and participate in 2.57 marathon events per year on average. The psychographic variables indicate respondents on average agree that running would be good for mental relief $(M=4.66)$, that the sport could be practiced everywhere $(M=4.65)$, that they would think of themselves as a runner $(M=4.41)$, and that running could be easily integrated into everyday life $(M=4.24)$. They agree to a lower extent to the following statements: I feel emotionally attached to other runners $(M=3.84)$, running is good for health $(M=3.77)$, and runners significantly differ from other sportsmen $(M=2.92)$. Respondents would rather not stop running when they had less time
Table 2

Descriptive Statistics

\begin{tabular}{lrr}
\hline Variable & \multicolumn{1}{c}{ Mean } & \multicolumn{1}{c}{$S D$} \\
\hline WTP_GERMAR & 78.06 & 28.98 \\
WTP_EUMAR & 102.81 & 67.45 \\
WTP_SEAMAR & 158.39 & 163.98 \\
WTP_GERTRA & 270.33 & 182.97 \\
WTP_EUTRA & 568.16 & 493.81 \\
WTP_SEATRA & $1,429.23$ & 892.69 \\
LN WTP_GERTRA & 4.29 & 0.35 \\
LN WTP_EUTRA & 4.52 & 0.45 \\
LN WTP_SEATRA & 4.85 & 0.59 \\
KM & 54.27 & 21.31 \\
MAR & 2.57 & 1.98 \\
SELF & 4.41 & 0.62 \\
HEALTH & 3.77 & .81 \\
STOP TIME & 2.44 & 1.07 \\
ATTACH & 3.84 & 0.71 \\
DIFF & 2.92 & 0.96 \\
ALLDAY & 4.24 & 0.71 \\
MENTAL & 4.66 & 0.49 \\
PLACE & 4.65 & 0.56 \\
ENDUR & 4.72 & 0.46 \\
AGE & 44.76 & 8.67 \\
INC & 5.67 & 2.23 \\
Share of respondents (in \%) & & \\
GENDER & 75.0 & \\
EDU & 65.7 & \\
\hline
\end{tabular}

available $(M=2.44)$ and when their running partners stopped running $(M=1.43)$.

With regard to WTP for participation in and traveling to marathon events, it can be seen that the average WTP slightly increases with the distance (from Germany) to the marathon event. This holds true for both the WTP for the registration fee and the WTP for traveling to the marathon event. Average WTP for the registration fee of a marathon in Germany amounts to $€ 78.06$ on average, for a marathon in Europe to $€ 102.81$, and for an overseas marathon to $€ 158.39$. The respondents stated they would be willing to pay on average $€ 270.33$ to travel to a marathon race in Germany, $€ 568.16$ to a marathon event in Europe, and $€ 1,429.23$ to an overseas marathon race (Table 2).

\section{Factor Analysis}

The results of the factor analysis are presented in Table 3. The factor solution explains $64.5 \%$ of 
the output variance. This mediocre quality can be considered acceptable, as the factor loadings of all variables are over 0.4 (Pohlman, 2004) and 0.5 (Backhaus, Erichson, Plinke, \& Weiber, 2008), depending on the threshold that is used. Altogether, four factors were extracted and thus the total number of psychographic variables could be successfully reduced to a smaller number of factors. Three variables load on the first factor. This factor is labelled CASUAL as it includes variables that relate to running as an activity that is easy to accomplish, good for mental relief, and independent of place. The second factor is described by the health and endurance benefits respondents attribute to running and the self-concept of the runner and is therefore labelled HEALTH-CONSCIOUS. The third factor is named IDENTITY-DRIVEN as the variables of this factor refer to the attachment to the sport and the differences from other sports. The fourth factor is named SWITCHING as it represents those people who would easiest stop running if they were scarce of time.

\section{Determinants of WTP}

The results of the regression analyses are summarized in Table 4. They show that only a few variables significantly determine the WTP for traveling to a marathon event. In Model 1, the factors CASUAL and HEALTH-CONSCIOUS as well as income (INC) have a significant positive impact on WTP for traveling to a marathon race in Germany. This means that health-conscious runners who are used to integrating their running into everyday life and have a high income stated a higher WTP. Behavioral variables had no significant impact on WTP in this model. The WTP for a marathon event in Europe (Model 2) is significantly determined by HEALTH-CONSCIOUS, $\mathrm{KM}$, and INC with all variables impacting positively on WTP. Runners with high income who run many kilometers per week and assign health benefits to running were more likely to state a high WTP. The results of the regression model for WTP for traveling to a marathon overseas (Model 3) reveal that only demographic variables determine WTP significantly. The variables AGE and INC have a significant positive impact on WTP, indicating that older and affluent runners would be more likely to state a high WTP. The regression models explain 14.5\% (Model 1), 14.2\% (Model 2), and $11.7 \%$ (Model 3 ) of the variation in the dependent variable, respectively.

\section{Discussion}

The participant characteristics confirm the sample structure of previous studies, suggesting that the typical marathon runner is a well-educated and affluent male in the 40s (e.g., Chalip \& McGuitry, 2004; Funk et al., 2007). Thus, the sample structure

Table 3

Results of the Factor Analysis

\begin{tabular}{lcccc}
\hline Variable & F1: & F2: & F3: & F4: \\
\hline SELF & CASUAL & HEALTH-CONSCIOUS & IDENTITY-DRIVEN & SWITCHING \\
HEALTH & & 0.663 & & 0.882 \\
STOP TIME & & 0.688 & & 0.728 \\
ATTACH & & & 0.778 & \\
DIFF & & & & \\
ALLDAY & 0.745 & & & 0.973 \\
MENTAL & 0.648 & & & 1.072 \\
PLACE & 0.590 & & 11.910 & \\
ENDUR & 2.525 & 1.237 & & \\
Eigenvalue & 28.051 & 13.744 & & \\
Variance explained in \% (64.515) & 0.707 & & & \\
KMO & $\chi^{2}=294.042^{*}$ & & & \\
Bartlett's test for sphericity & & & & \\
\hline
\end{tabular}

Note: Principal components analysis with varimax rotation; ${ }^{*} p<0.01$. KMO, Kaiser-Meyer-Olkin statistic. 
Table 4

Results of the Regression Analyses for WTP for Traveling to Marathon Events

\begin{tabular}{lccc}
\hline & Model 1: LN WTP_GERTRA & Model 2: LN WTP_EUTRA & Model 3: LN WTP_SEATRA \\
\hline Constant & $4.719(15.544)^{* * *}$ & $5.162(17.666)^{* * *}$ & $5.750(15.934)^{* * *}$ \\
CASUAL & $0.177(2.603)^{* * *}$ & $0.046(0.869)$ & $-0.031(-0.491)$ \\
HEALTH-CONSCIOUS & $0.127(2.515)^{* *}$ & $0.167(.3 .086)^{* * *}$ & $0.109(1.530)$ \\
IDENTITY-DRIVEN & $0.052(1.218)$ & $0.043(0.996)$ & $0.018(0.368)$ \\
SWITCHING & $0.016(0.312)$ & $-0.028(-0.540)$ & $-0.069(-0.707)$ \\
KM & $0.003(1.328)$ & $0.004(1.789)^{*}$ & $0.006(1.424)$ \\
MAR & $-0.028(-1.146)$ & $0.018(0.739)$ & $0.022(0.622)$ \\
GENDER & $-0.174(-1.503)$ & $-0.142(-1.257)$ & $0.107(0.458)$ \\
AGE & $0.006(1.196)$ & $0.009(1.563)$ & $0.011(2.174)^{* *}$ \\
EDU & $-0.049(-0.494)$ & $0.049(0.484)$ & $-0.111(-0.767)$ \\
INC & $0.075(3.491)^{* * *}$ & $0.059(2.280)^{* *}$ & $0.063(2.617)^{* * *}$ \\
$R^{2}$ & 0.145 & 0.142 & 0.117 \\
$F$ & 4.876 & 3.072 & 4.870 \\
$P$ & $<0.001 * * *$ & $0.001 * * *$ & $<0.001 * * *$ \\
\hline
\end{tabular}

Note: Displayed are the unstandardized coefficients, $t$ values in brackets; robust standard errors are reported; ${ }^{*} p<0.1, * * p<0.05$, $* * * p<0.01$.

suggests that the typical marathon runners have participated in the survey and therefore the sample size should not be a major concern. Stated WTP for traveling to marathon events was higher than in previous research on WTP for active sport consumption (e.g., Johnson et al., 2007; Wicker, 2011) and for hosting sport events (e.g., Atkinson et al., 2008). On the basis of the stated WTP values, it seems that marathon runners demonstrate a high financial involvement in their sport in addition to their time involvement for practice. Average stated WTP increases with increasing travel distance to the marathon event, a finding that supports the validity of the WTP estimates. The WTP estimates seem plausible because they mirror the travel expenses that have to be made in general for traveling to different marathon events: It seems realistic to pay $€ 270$ to travel to a marathon in Germany, $€ 568$ to a marathon in Europe, and $€ 1,429$ to an overseas marathon event.

The results of the factor analysis are in accordance with prior research insofar that runners form a particular subculture (Shipway \& Jones, 2008). Yet, it is also evident that there are differences between several components of running, one focusing on the identity theme, whereas another component is also that running might be given up when time is scarce. These findings correspond with other research that suggests differentiating between joggers (Smith, 1998; Yair, 1992) represented in this study as the CASUAL and SWITCHING components, and runners (Smith, 1998; Yair, 1992) formed by the components HEALTH-CONSCIOUS and IDENTITY-DRIVEN. It can be assumed, on the basis of those previous findings and the results of the factor analysis, that these components are immanent in all runners, however the degree differs, turning some runners into joggers and vice versa.

Moreover, as already pointed out in the literature review, being health conscious is a dominant theme in leisure and tourism (Mikunda, 2002; Pine \& Gilmore, 1999). The results suggest that marathon running is definitely perceived by runners as contributing to one's health. This might be surprising for those who do not run because anecdotal evidence rather suggests that moderate distances are good instead of overdoing it and running too long. Being aware of the particular subculture of running, this result is actually not surprising as it contributes to forming a particular running identity (Shipway \& Jones, 2008).

The regression results show that income is an important determinant of WTP for traveling to either marathon event, indicating that high income represents a precondition for participating in and traveling to events. The positive income effect on WTP is in accordance with previous research (Atkinson et al., 2008; Owen, 2006; Wicker, 2011). The results of the regression analyses indicate that 
psychographics are significant drivers of WTP for participation in a marathon race in Germany and Europe; however, they did not explain WTP for participation in an overseas marathon. One explanation for this can be that it comes down to an individual's income for those long travel distances at the end of the day. Age had a significant positive impact on WTP for participation in an overseas marathon, suggesting that older runners would be more likely to collect places and therefore stated a higher WTP. Interestingly, only one behavioral variable (number of kilometers per week) had a significant positive impact on WTP for a marathon in Europe. It seems that particularly runners with high training efforts want to travel to a marathon within Europe where they could probably challenge their personal best.

This study has some limitations. The regression models indicated that WTP for participation in marathon events was difficult to explain. Only a few variables were significant and the explained variance $\left(R^{2}\right)$ was only between $11.7 \%$ and $14.7 \%$. This finding can be in part a result of the relatively small sample size, as statistically significant effects are more likely in large samples. With regard to the relatively low share of explained variance, it can be suggested that further variables are needed to explain the WTP for traveling to marathon events. Possible variables in this regard could be lifestyle and social evaluations of sports, or body image. Another limitation relates to the measurement of WTP. Although a few examples for travel expenses were provided, more examples could have been provided to ensure that each respondent includes the same travel expenses in his/her individual calculation. Although the WTP data have been checked for content validity and plausibility and all values seemed realistic, the concern of a hypothetical bias still remains. It cannot be said with certainty that the respondents would pay the stated WTP. Moreover, the study is based only on cross-sectional data that simply measure the status quo. It could also be interesting to analyze the development of WTP depending on changes in behavioral, psychographic, and demographic characteristics.

Nevertheless, the findings of the current study have implications for event managers of marathon races. It becomes clear that although all runners have the same objective of completing the race, there are motives they evaluate differently. Event organizers need to be aware of the diverse underlying motives when communicating with the vast running community. The big races such as the World Majors (Boston, London, Berlin, Chicago, and New York) already serve these different needs with side events focusing on health issues (targeting the healthconscious group) or other events highlighting the extraordinary place of the race and the experience with friends (targeting the identity-driven group), or the ease of running itself (targeting the casual group). Smaller events often do not follow such an approach but can be recommended to do so. This is particularly important when considering both the runner's WTP and the positive influence of being health conscious on WTP. These health-conscious runners are indeed willing to pay for national and European races and event organizers should target this type of runner specifically.

\section{Conclusions}

The current study investigated the WTP for participating in and traveling to marathon events in Germany, in Europe, and overseas using quantitative data on marathon runners in Germany. A factor analysis was conducted with psychographic variables resulting in four factors labeled casual, health conscious, identity driven, and switching. The regression results revealed that casual and health-conscious runners with high income were more likely to state a high WTP for traveling to a marathon in Germany, healthconscious runners with high income and who are running many kilometers per week stated a higher WTP for a marathon in Europe, and older runners with high income were willing to pay more for an overseas marathon.

As this study was the first to analyze the WTP for participation in marathon events, more research on this topic is needed in the future. Future research should clarify the results and gain further insights into the importance of psychographic, behavioral, and demographic variables. Collecting larger samples and comparing data among different countries can also be considered fruitful for future studies. Another avenue for future research can be to compare the WTP for participation in and traveling to specific marathon events (e.g., Boston marathon vs. New York marathon). 


\section{References}

Atkinson, G., Mourato, S., Szymanski, S., \& Ozdemiroglu, E. (2008). Are we willing to pay enough to 'back the bid'?: Valuing the intangible impacts of London's bid to host the 2012 Summer Olympic Games. Urban Studies, 45(2), 419-444.

Backhaus, K., Erichson, B., Plinke, W., \& Weiber, R. (2008). Multivariate Analysemethoden. Berlin: Springer.

Balderjahn, I. (2003). Erfassung der preisbereitschaft. In H. Diller \& A. Herrmann (Eds.), Handbuch Preispolitik (pp. 388-404). Wiesbaden, Germany: Gabler.

Bojanic, D. C., \& Warnick, R. B. (2012). The role of purchase decision involvement in a special event. Journal of Travel Research, 51(3), 357-366.

Bortz, J. (2005). Statistik für Human- und Sozialwissenschaftler (6th ed.). Heidelberg, Germany: Springer.

Bosjnak, M., \& Tuten, T. L. (2003). Prepaid and promised incentives in Web surveys. Social Science Computer Review, 21(2), 208-217.

Breidert, C. (2005). Estimation of willingness-to-pay. Theory, measurement, and application. Dissertation, Wirtschaftsuniversität Wien, Vienna.

Brennan, M. (1992). The effect of a monetary incentive on mail survey response rates - new data. Journal of the Market Research Society, 34(2), 173-177.

Cannon, T. F., \& Ford, J. (2002). Relationship of demographic and trip characteristics to visitor spending: An analysis of sports travel visitors across time. Tourism Economics, 8(3), 263-271.

Carlsson, F., \& Martinsson, P. (2001). Do hypothetical and actual marginal willingness to pay differ in choice experiments? Journal of Environmental Economics and Management, 41, 179-192.

Carson, R. T., Wright, J., Carson, N., Alberini, A., \& Flores, N. (1993). A bibliography of contingent valuation studies and papers. La Jolla, CA: Natural Resource Damage Assessment.

Chalip, L., \& McGuitry, J. (2004). Bundling sport events with the host destination. Journal of Sport Tourism, 9(3), 267-282.

Chhabra, D., Sills, E., \& Rea, P. (2002). Tourist expenditures at heritage festivals. Event Management, 7(4), 221-230.

Cobanoglu, C., \& Cobanoglu, N. (2003). The effect of incentives in web surveys: Application and ethical considerations. International Journal of Market Research, 45(4), 475-488.

Cobb, S., \& Olberding, D. J. (2007). The importance of import substitutions in marathon economic impact analysis. International Journal of Sport Finance, 2(2), 108-118.

Daniels, M. J., \& Norman, W. C. (2003). Estimating the economic impacts of seven regular sport tourism events. Journal of Sport Tourism, 8(4), 214-222.

Diller, H. (2000). Preispolitik (3rd ed.). Stuttgart, Germany: Kohlhammer.

Funk, D. C., Toohey, K., \& Bruun, T. (2007). International sport event participation: Prior sport involvement; destination image; and travel motives. European Sport Management Quarterly, 7(3), 227-248.

Gratton, C., \& Taylor, P. (2000). Economics of sport and recreation. London: Spon Press.

Hair, J., Black, W., \& Babin, B. (2006). Multivariate data analysis. Upper Saddle River, NJ: Pearson Prentice Hall.

Hallmann, K., Kaplanidou, K., \& Breuer, C. (2010). Event image perceptions among active and passive sport tourists at marathon races. International Journal of Sports Marketing and Sponsorship, 12(1), 37-52.

Johannesson, M., Liljas, B., \& Johansson, P. (1998). An experimental comparison of dichotomous choice contingent valuation questions and real purchase situations. Applied Economics, 30, 643-647.

Johnson, B. K., Whitehead, J. C., Mason, D. S., \& Walker, G. J. (2007). Willingness to pay for amateur sport and recreation programs. Contemporary Economic Policy, 25(4), 553-564.

Kalish, S., \& Nelson, P. (1991). A comparison of ranking, rating, and reservation price measurement in conjoint analysis. Marketing Letters, 2(4), 327-335.

Kaplanidou, K., Funk, D. C., Buta, N., \& Goutzioupas, G. (2009). The event image of the Athens Marathon from the Sport Tourist Marathon Runners' perspective: A qualitative and quantitative approach. In H. Westerbeek \& P. G. Fahlstrom (Eds.), Conference Proceedings of the 17th EASM Conference "Best practice in sport facility and event management" (pp. 219-220). Nieuwegein, the Netherlands: Arko Sports Media.

Klose, T. (1999). The contingent valuation method in health care. Health Policy, 47, 97-123.

Kruger, M., \& Saayman, M. (2012). Creating a memorable spectator experience at the Two Oceans Marathon. Journal of Sport \& Tourism, 17(1), 63-77.

MacKinnon, J. G., \& White, H. (1985). Some heteroskedasticity-consistent covariance matrix estimators with improved finite sample properties. Journal of Econometrics, 29(3), 305-325.

Mead, L. A., Ford, D. E., Roth, L. H., Beach, C. L., \& Klag, M. J. (2000). Feasibility of using recipients of health promotional newsletters for post-marketing surveillance. Journal of Clinical Epidemiology, 53(6), 653-660.

Mikunda, C. (2002). Marketing spüren: Willkommen am dritten Ort. Frankfurt and Wien: Ueberreuter.

Mullin, B. J., Hardy, S., \& Sutton, W. A. (2007). Sport marketing. Champaign, IL: Human Kinetics.

Ogles, B. N., \& Masters, K. S. (2003). A typology of marathon runners based on cluster analysis of motivations. Journal of Sport Behavior, 26(1), 69-75.

Owen, J. (2006). The intangible benefits of sports teams. Public Finance and Management, 6(3), 321-345.

Pennington-Gray, L., \& Holdnak, A. (2002). Out of the stands and into the community: Using sports events to promote a destination. Event Management, 7(3), $177-186$.

Pine, B. J., \& Gilmore, J. H. (1999). The experience economy. Boston: Harvard Business Press. 
Pohlman, J. T. (2004). Use and interpretation of factor analysis. The Journal of Educational Research, 98(1, Special Issue on Methodology), 14-22.

Rohm, A. J., Milne, G. R., \& McDonald, M. A. (2006). A mixed-method approach for developing market segmentation typologies in the sports industry. Sport Marketing Quarterly, 15(1), 29-39.

Rollins, R., \& Trotter, W. (1999-2000). Public attitudes regarding user fees in provincial forest lands. Leisure: Journal of the Canadian Association for Leisure Studies, 24(1/2), 139-159.

Sattler, H., \& Nitschke, T. (2003). Ein empirischer Vergleich von Instrumenten zur Erhebung von Zahlungsbereitschaften. Schmalenbachs Zeitschrift für betriebswirtschaftliche Forschung (zfbf), 55, 364-381.

Scheerder, J., Vos, S., \& Pauwels, G. (2009). Actuele omvang van de Vlaamse loopsportmarkt: Socio-culturele en socio-economische profielen van loopsporters. In J. Scheerder \& F. Boen (Eds.), Vlanderen loopt! Sociaalwetenschappelijk onderzoek naar de loopsportmarkt (pp. 153-218). Gent, Belgium: Academia Press.

Seip, K., \& Strand, J. (1992). Willingness to pay for environmental goods in Norway: A contingent valuation study with real payment. Environmental and Resource Economics, 2, 91-106.

Shank, M. D., Darr, B. D., \& Werner, T. C. (1990). Increasing mail survey response rates: Investigating the perceived value of cash versus non-cash incentives. Applied Marketing Research, 30(3), 28-32.

Shilbury, D., Westerbeek, H., Quick, S., \& Funk, D. C. (2009). Strategic sport marketing. Crows Nest, NSW: Allen \& Unwin.

Shipway, R., \& Jones, I. (2007). Running away from home: Understanding visitor experiences and behaviour at sport tourism events. International Journal of Tourism Research, 9(5), 373-383.

Shipway, R., \& Jones, I. (2008). The great suburban everest: An insider's perspective on experiences at the 2007 Flora London Marathon. Journal of Sport and Tourism, 13(1), 61-77.

Singer, R. (2002). Verfahren zur festlegung von stichproben. In R. Singer \& K. Willimczik (Eds.),
Sozialwissenschaftliche Forschungsmethoden in der Sportwissenschaft (pp. 55-66). Hamburg, Germany: Czwalina.

Smith, S. L. (1998). Athletes, runners, and joggers: Participantgroup dynamics in a sport of 'individuals'. Sociology of Sport Journal, 15(2), 174-192.

Späth, H. (1975). Cluster-Analyse-Algorithmen. München, Germany: Oldenbourg Publishing.

Statista GmbH. (2011). Number of marathon events in Germany 1999-2010. Retrieved from http://de.statista. com/statistik/daten/studie/6021/umfrage/anzahl-dermarathon-laeufe-in-deutschland-seit-1999/

Süssmuth, B., Heyne, M., \& Maennig, W. (2010). Induced civic pride and integration. Oxford Bulletin of Economics and Statistics, 72(2), 202-220.

Tabachnick, B. G., \& Fidell, L. S. (2007). Using multivariate statistics. Boston, MA: Allyn \& Bacon.

Trail, G. T., \& James, J. D. (2001). The motivation scale for sport consumption: Assessment of the scale's psychometric properties. Journal of Sport Behavior, 24(1), 108-127.

van Selm, M., \& Jankowski, N. W. (2006). Conducting online surveys. Quality \& Quantity, 40, 435-456.

Völckner, F. (2006). Methoden zur messung individueller zahlungsbereitschaften: Ein überblick zum state of the Art. Journal für Betriebswirtschaft, 56, 33-60.

Weed, M., \& Bull, C. (2004). Sports tourism: Participants, policy and providers. London: Elsevier.

Wells, W. D. (1975). Psychographics: A critical review. Journal of Marketing Research, 12(5), 196-213.

White, H. (1980). A heteroscedasticity-consistent covariance matrix estimator and a direct test for heteroscedasticity. Econometrica, 48(4), 817-838.

Wicker, P. (2011). Willingness-to-pay in non-profit sports clubs. International Journal of Sport Finance, 6(2), 155-169.

Yair, G. (1990). The commitments to long distance running and levels of activity: Personal or structural? Journal of Leisure Research, 22(3), 213-227.

Yair, G. (1992). What keeps them running? The 'circle of commitment' of long distance runners. Leisure Studies, 11(3), 257-270. 